University of Rhode Island

DigitalCommons@URI

Open Access Master's Theses

1988

\title{
A Cluster Analysis of Temperament Using the Student Personality Assessment Form
}

Karen Corwin Mook

University of Rhode Island

Follow this and additional works at: https://digitalcommons.uri.edu/theses

\section{Recommended Citation}

Mook, Karen Corwin, "A Cluster Analysis of Temperament Using the Student Personality Assessment Form" (1988). Open Access Master's Theses. Paper 1705.

https://digitalcommons.uri.edu/theses/1705

This Thesis is brought to you for free and open access by DigitalCommons@URI. It has been accepted for inclusion in Open Access Master's Theses by an authorized administrator of DigitalCommons@URI. For more information, please contact digitalcommons-group@uri.edu. 
A CLUSTER ANA LYSis OF TEMPERAMENT USING

THE STUDENT PERSONALITY ASSESSMENT FORM

BY

KAREN CORWIN MOOK

A MASTERS THESIS SUBMITTED IN PARTIA L FULFI LLMENT OF THE REQUIREMENTS FOR THE DEGREE OF

MASTER OF ARTS

IN

PSYCHOLOGY

UNIVERSITY OF RHODE ISLAND

1988 


\section{ABSTRACT}

Temperament theory considers "normal" personality variables among children and subsequently categorizes them along a continuum of three basic types: Easy, Slow-to-WarmUp, and Difficult. This paper examines whether empiricallybased methods of investigation (cluster analysis) generate natural groupings of different temperament types among young children from temperament based data. Kindergarten, first, and second grade children were rated on the student Personality Assessment Form (SPAF), a derivative of Thomas and Chess' Teacher Temperament Questionnaire (TTQ). This paper also examines the relationship between derived temperament groups and school achievement through a multivariate analysis of variance. Results indicate that within the normal population, many children do exhibit one of a few temperament types as measured by the SPAF. Furthermore, there is evidence to support the expected relationship between temperament and school achievement: more difficult groups achieve significantly below the characteristically easier types. 


\section{ACKNOWLEDGEMENTS}

I wish to thank my husband, Bill, for his continued support and my daughter, Louisa, for her patience during this long process of meeting the requirements for a Master's degree. I also wish to thank my major professor, Jan Kulberg, for her inspiration in child development and research. Special thanks also to my committee: Wayne Velicer, Lisa Harlow, and Gwen Rae, for their assistance and encouragement. And thanks to Earl H. Baker for the use of his data. 
TABLE OF CONTENTS

ACKNOWLEDGEMENTS. . . . . . . . . . . . . . . . iii LIST OF TABLES . . . . . . . . . . . . . . . vi vi LIST OF FIGURES . . . . . . . . . . . . . . . . vii

I. Introduction . . . . . . . . . . . . . 1

II. Study One: Cluster Analysis of the student Personality Assessment Form (SPAF). . . . . . . 13

Method ....................13

Sample . . . . . . . . . . . . 13

Instruments . . . . . . . . . . . . . . .14

Procedure . . . . . . . . . . . . .15

Results . . . . . . . . . . . . . 20

Discussion . . . . . . . . . . . . . . 32

III. Study Two: A Multivariate Analysis of Variance Comparing Six Clusters . . . . . . . . 33

Method . . . . . . . . . . . . . . . 33

Sample . . . . . . . . . . . . . .33

Instruments . . . . . . . . . . . 33

Results . . . . . . . . . . . . 35 
V. Discussion . . . . . . . . . . . . . . 39 BIBLIOGRAPHY. . . . . . . . . . . . . . . . . . . . 44

\section{APPENDICES}

A. Cluster Stability Across Ward's and Group Average Methods $\mathrm{N}(1)$. . . . . . . . . . . . . 47

B. Cluster Stability Across Ward's and Group Average Methods N (2) . . . . . . . . . . . . . 49

C. Student Personality Assessment Form (SPAF) . . . . .51

D. Tukey Test Results: Significant Mean Reading Score Differences Between Clusters in Second Data Set. . . . . . . . . . . . . . . 54

E. Tukey Test Results: Significant Mean Math Score Differences Between Clusters in Second Data set... . . . . . . . . . . . . . . . 56 
1. Means and Standard Deviations of SPAF Components: Non-compliance, Extroversion, Interpersonal Affect for All Six Clusters, N (1) . . . . . . . . 22

2. Means and Standard Deviations of SPAF Components: Non-compliance, Extroversion, Interpersonal Affect for All Six Clusters, N (2) . . . . . . . . 29

3. Cluster Means and Standard Deviations for CTBS Math and Reading Stanines, $\mathrm{N}(1)$. . . . . . . . 36

4. Cluster Means and Standard Deviations for CTBS Math and Reading Stanines, N (2) . . . . . . . . . . 37

5. Cluster Stability Across Ward's and Group Average Methods, N (1) . . . . . . . . . . 48

6. Cluster Stability Across Ward's and Group Average Methods, N (2) . . . . . . . . . 50

7. Tukey Test Results: Significant Mean Reading Score Differences Between Clusters in Second Data Set . . .55

5. Tukey Test: Significant Mean Math Score Differences Between Clusters in Second Data Set . . .57 


\section{LIST OF FIGURES}

1. Mean scores on Non-compliance, Extroversion, and Interpersonal Affect for Easy-Compliant cluster . . 23

2. Mean scores on Non-compliance, Extroversion, and Interpersonal Affect for Easy-Assertive cluster . . .24

3. Mean scores on Non-compliance, Extroversion, and Interpersonal Affect for Moderately DifficultExtroverted cluster . . . . . . . . . . . . 25

4. Mean scores on Non-compliance, Extroversion, and Interpersonal Affect for Easy-Withdrawn cluster . . .26

5. Mean scores on Non-compliance, Extroversion, and Interpersonal Affect for Difficult-Withdrawn cluster 32 . . . . . . . . . . . . . . . 27

6. Mean scores on Non-compliance, Extroversion, and Interpersonal Affect for Difficult-Extroverted cluster . . . . . . . . . . . . . . . 28 
Temperament theory considers "normal" personality variables among children and subsequently categorizes them along a continuum of three basic types: Easy, Slow-To-WarmUp, and Difficult. Temperament assumes a genetic contribution to the development of personality types and can be viewed as the core of personality. Different from ability or motivation, the what and why of behavior, temperament describes the style of behavior (Thomas, Chess, Birch, Hertzig, \& Korn, 1963; Martin, 1983).

The utility of categorizing children according to a temperament type is not in merely labeling them as members of one group or another. Rather, there is evidence to suggest that the relationship between temperament type and a child's environment may be significantly related to normal or dysfunctional development (Thomas, Chess, Birch, Hertzig, \& Korn, 1963; Martin, Drew, Gaddis, \& Mosely, 1988; Baker \& Velicer, 1986; Barron \& Earls, 1984; Lerner, 1983). Classification is, therefore, potentially useful for intervention and prevention of abnormal development. Early childhood is a particularly appealing age group to study because of early intervention and prevention effectiveness.

The current paper reviews the theoretical premises of temperament in detail before presenting its empirical purpose. The problems in operationally defining and measuring constructs are also addressed. 
In the current study, it was hypothesized that empirically based methods of investigation would generate natural groupings of different temperament types of children from temperament based data. Furthermore, it was predicted that the groupings would reflect the theoretical premises of the NYLS theory -- that some form of the easy, difficult, and slow-to-warm-up groups would emerge. As far as the current author found in her extensive review of the literature, these questions had not been previously investigated directly with empirical methods. In order to do so, cluster analysis, an empirical method that groups subjects who are similar to one another was used.

Subsequently, when natural groupings of children were recovered from the temperament data, relationships between the derived temperament types and school achievement were explored through a multivariate analysis of variance (MANOVA). This served to examine the relationship between temperament type and academic achievement which was viewed as one outcome measure of development.

The original research that focused on the three predominanat types of temperament: the Easy, the SIow-ToWarm-Up, and the Difficult types, is described in the New York Longitudinal study (NYLS: Thomas, Chess, Birch, Hertzig, \& Korn, 1963). The NYLS authors called these types "constellations."

The first constellation, the Easy Child, is just that - easy. The typical child in this constellation responds positively to new stimuli, adapts readily to change, and 
handles frustration with little aggravation. He or she expresses mild moods and approaches life in a positive manner. As an infant, the Easy Child establishes regular sleep and feeding schedules quickly, experiments with new foods, is friendly, and even smiles at strangers. When school-age, he or she adapts easily to a change in schools or classrooms. Eager to participate in novel games and willing to abide by new rules, the Easy child is generally a pleasure for his or her parents, pediatrician, or teacher. Relying primarily on their clinical expertise and rationally based information, the NYLS authors determined that the Easy Child constellation represented about $40 \%$ of their NYLS sample.

Unlike the Easy Child, the typical child in the slowTo-Warm-Up constellation tends to respond negatively to new stimuli. Through repeated contact, however, this type of child usually adjusts positively, albeit slowly. In either case, whether positive or negative, the Slow-To-Warm-Up Child's reaction is consistently mild. If meeting a stranger or trying a new food, for example, the slow-ToWarm-Up child typically responds negatively at first; but, when given the opportunity to re-experience the new situation without pressure and over time, he or she eventually becomes interested and involved (Thomas \& Chess, 1977). Others have described a similar disposition in young children which they have referred to as an inhibited behavioral style (Garcia Coll, Kagan, \& Reznick, 1984). In the NYLS sample, Thomas and chess calculated that the slow- 
To-Warm-Up constellation accounted for some 15\% of the children.

The last constellation, the Difficult Child, occurred least frequently in the NYLS sample accounting for about $10 \%$ of the population. The clinical identification of this child, however, was most pronounced (see also Bates, Freeland, \& Lounsburry, 1979). This child is difficult for parents, teachers, and pediatricians to interact with. Having a negative disposition and the tendency to withdraw from new stimuli, the Difficult child adapts slowly at best and often does not accept change. This child also displays intense moods that are frequently negative. He or she cries often and loudly; any frustration can result in violent temper tantrums. The Difficult infant has irregular biological functions such as sleeping and feeding. Unlike the Easy and the Slow-To-Warm-Up Child, he or she requires prolonged adjustment to new routines, people, or situations (Thomas \& Chess, 1977).

About $35 \%$ of the child population does not fit into one of these three temperamental types. As Thomas and Chess explained, some children exhibit varied combinations of temperament traits, while others demonstrate varying degrees within the three general types: there are extremely easy children just as there are those who are only moderately difficult. Consequently, Thomas and Chess emphasized that their three described constellations represent only some of the variations within normal limits (1977). 
Impressed by the important implications for child rearing that emerged from their theory, Thomas and Chess surmised that a child's healthy development depended in a major way on the "goodness-of-fit" or a positive interactive process that existed between the child's temperament and his or her environment. Subsequently, the authors found some empirical support for this hypothesis in the NYLS samples. For example, "Difficult" children were more likely to develop behavior disorders if their parents were inconsistent, impatient, or dominating in their child rearing practices. Conversely, Easy children were more capable of adapting to a wide variety of parental approaches and often proved to be resilient to stressful environments. In no case, the NYLS authors stressed, did a particular composition of temperament determine healthy or deviant development. Rather, outcome was the product of the interaction between the child's individual temperamental style with significant features in his environment. The significance of temperament was that by manipulating the "goodness-of-fit" between a child and his environment, deviant development might be ameliorated or even prevented (1977).

Because of practical appeal, the theoretical premises of the NYLS have inspired much research. Problems, however, in operationalizing the relevant constructs and therefore measuring them have persisted throughout. For example, to date there remains no universally accepted definition of temperament. 
Instead, three consistent themes emerge in the literature. First, most agree that temperament consists of stable traits which are inherited, controlled in part by the central nervous system, and described in terms of the quality of emotions. Second, most temperament theorists do not believe that these traits are immutable or even necessarily present at birth. And third, like most developmentalists, this group takes an interactionist perspective arguing that although temperament can be assessed at any time, the measure is variable because it is the result of the complex interaction of genetics, maturation, and the environment (Martin, 1983; Seifer, 1986).

In addition to being poorly defined, temperament remains difficult to measure. Some of the difficulty is attributed to the developmental nature of the construct, and some to the theoretically important but scientifically unreliable information generated in the NYLS. For example, Thomas et al. determined nine dimensions of behavior which they considered important, but which were based on clinical observation: activity level, rhythmicity, approach or withdrawal, adaptability, threshold or responsiveness, intensity of reaction, quality of mood, distractibility, and persistence. The NYLS authors designed questionnaires to measure the presence of each in individual children. The parent questionnaires were supposed to measure all nine dimensions whereas the teacher questionnaires excluded rhythmicity because this dimension was identifiable only by 
behavior measured over a twenty-four hour period.

Neither the nine nor the eight dimensions of temperamental behavior have been reproduced empirically. Factor analysis of the NYLS scales as well as other measures of temperament produces three, four, and sometimes five of the nine that are identified in the original scale. Construct validity of the scales, therefore, is poor. The questionnaires are not measuring the nine dimensions delineated in the NYLS. Furthermore, because the test-retest reliabilities of the factors that do emerge are only moderate, there is more skepticism about not only what is being measured but also the reliability of these socalled stable traits persisting over time. issues in temperament research, Hubert and his colleagues found that the lack of reliability and validity in the NYLS scales underlies much of the subsequent research on temperament (Hubert, Wachs, Peters-Martin, \& Gandour, 1982). Few researchers have revised the scales to make them psychometrically sound. Consequently, in 1982, Hubert et al. concluded that many available instruments are inadequate derivatives of the NYLS.

Since this review, some researchers have focused on constructing psychometrically sound scales. Baker and Velicer (1986), for example, reconstructed the NYLS Teacher Temperament Questionnaire (TTQ) and named the resulting new instrument the Student Personality Assessment Form (SPAF). A 34-item, objective, teacher rating scale, the SPAF is 
appropriate for pre-schooì and elementary school children. In the research that focused on scale construction, Baker and Velicer used a principal components analysis and found that the SPAF produces three stable components which they described as: (1) Non-compliance, a summary of inattentiveness, distractibility, and persistence; Extroversion, a measure of lack of shyness, and comfort in new situations and social interactions; and (3) Interpersonal Affect, a measure of cooperation with the tendency to be argumentative. Derived alpha coefficients for the three components were $.92, .83$, and .86 respectively, indicating that the scale has reliable internal consistency (Baker \& Velicer, 1986). In subsequent research, Baker and Velicer replicated these results and validated their scale by correlating its content with the Devereux Elementary Behavior Rating Scale (DESB), a measure of school adjustment. The two authors found the DESB significantly related to the SPAF and were therefore able to operationally define three stable dimensions of student personality.

Similarly, Martin (1987) examined the reliability of both the NYLS Parent Temperament Questionnaire (PTQ) and the TTQ by evaluating the internal consistency of the scales with coefficient alpha and mean interitem correlation. Finding all values unacceptably low, Martin rewrote many items and produced derivatives of the scales which he named the Parent and Teacher Forms of the Temperament Assessment Battery. Useful for 3 to 7-year-old 
children, both rating scales are objective and consist of 48 items which are designed to measure activity level, adaptability, approach/withdrawal, emotion intensity, distractibility, and persistence. Like the SPAF, factor analysis of each form produces three stable factors: emotionality, persistence, and sociability (Martin, 1983). Lerner and his colleagues (Lerner, Palermo, Spiro, \& Nesselroade, 1982) at Pennsylvania State University have developed a short, moderately-reliable scale that measures five of the nine dimensions of temperament empirically. Using factor analysis, the 89-item scale which they call the Dimensions of Temperament Scale (DOTS), is reduced to five stable factors: activity level, attention span/distractibility, adaptability/approach-withdrawal, rhythmicity, and reactivity. Each of these has been reproduced across three age samples: preschool, middleschool, and college students. What is perhaps most noteworthy about this scale is not only the increased number of stable dimensions that are produced, but also its verified level of content and face validity. Experimentally blind, expert raters were able to categorize $89 \%$ of the scale items according to the nine dimensions defined in the NYLS. Thus, the DOTS appears to maintain theoretical integrity which is supported by empirical analysis.

Despite all the difficulty in measuring the nine original dimensions of temperament, research has demonstrated impressive relationships between temperament 
and cognitive ability, academic achievement, and psychopathology (Martin, Drew, Gaddis, \& Mosely, 1988; Baker \& Velicer, 1986; Martin \& Pfeffer, 1985; Barron \& Earls, 1984; Lerner, 1983; Hubert et al., 1982). For example, based on research in which they used the SPAF, the DESB, and measures of achievement, Baker and Velicer (1986) concluded that there is a significant relationship between academic achievement and temperament, and between school adjustment and temperament. Their 43 item SPAF predicted reading and math achievement scores on the comprehensive Test of Basic Skills (CTBS) with multiple regression coefficients of .57 and .44 respectively while the three components of the SPAF: Non-compliance, Extroversion and Interpersonal Affect were significantly correlated with the DESB (Multiple R coefficients of $.88, .70$ and .86 respectively).

Similarly, in her study of 99 eighth-graders that used the DOTS, academic grades, Coopersmith's Self-Esteem Inventory, and her own peer relations' scale, J. Lerner (1983) found a significant correlation between temperament and school adjustment.

In some cases, particular temperament variables have been found to be predictors. For example, Martin (1987) reports on results which have been replicated with six samples of 5 and 6 year old children demonstrating that of the nine dimensions, persistence is the most significant predictor of achievement and scholastic ability, but that distractibility, adaptability, and activity level also make 
significant contributions. Similarly, based on their study of 90 three year olds, Barron and Earls (1984) concluded that temperamental inflexibility is one of three significant variables in predicting behavior disorders.

In summary, temperament research demonstrates promising prospects for discovering important information that will contribute to understanding child behavior. It is critical, however, that investigators use the reliable and valid scales that are available in order to produce reliable and valid research results. The intent of the present study was to further analyze the reliable and validated SPAF data collected in the Baker/Velicer study. Specifically, the present study investigated two questions that are central to the NYLS theory: (1) Do individual children tend to exhibit one of a few personality or temperament types? (2) If so, are these types also different from one another in terms of their development? School achievement is used as one differentiating measure of development.

In order to address these questions, the current author used cluster analysis, a multivariate research method that groups subjects who are most alike. Although seven major families of cluster analysis have been developed, the hierarchical agglomerative methods have been researched and used most in the social sciences. Consequently, this type was used in the present, exploratory research.

Subsequent to recovering the natural cluster structure 
within the SPAF data, a MANOVA was utilized to externally validate the generated clusters. Distinct clusters were treated as independent variables and compared to one another with measures of school achievement. In addition to seeking external evidence to further differentiate the recovered clusters from one another, the analysis was conducted to explore the relationship between temperament types and academic achievement. 
STUDY 1: CLUSTER ANALYSIS OF THE SPAF

Method

Sample

Two sets of data were collected for the construction and validation of the SPAF and both were the basis of the present cluster analysis. The first set of data was obtained by asking 25 kindergarten, first, and second grade teachers in a centrally located school district in Rhode Island to complete one questionnaire for each of ten randomly selected students. Fourteen of the 25 teachers who volunteered finished five to ten of the questionnaires. Three kindergarten teachers completed 25 questionnaires, six first grade teachers finished 58, and five second grade teachers finished 37 forms. The final sample size was 120 . Of these, teachers completed all the items on 102 questionnaires -- 18 were incomplete. Because a cluster analysis is sensitive to and possibly distorted by incomplete data and because there appears to be no biasing reason for the ommitted items, the incomplete data were excluded. The final sample size for this analysis was therefore 102 .

The second data set was collected one year later in the same school district but on different children. Again, kindergarten, first, and second grade teachers participated and the same procedure was used. This time six kindergarten teachers completed a total of 122 forms, six first grade teachers finished a total of 43 , and three 
second grade teachers completed 18 SPAF forms. The final sample size was 183. Again, teachers left some forms incomplete and consequently 129 complete forms were used in sample 2 .

\section{Instruments}

The instrument used in this study was the student Personality Assessment Form (SPAF) which is a derivative of the Teacher Temperament Questionnaire (TTQ), the teacher rating scale developed in the NYLS. Iike the TTQ, the SPAF is designed for use with pre-school and elementary school aged children and is completed by the teacher. A 34-item objective personality inventory, the SPAF is rated on a 5 point scale from 1 (Hardly Ever) to 5 (Almost Always).

The SPAF consistently measures three personality constructs: (1) Non-compliance, a summary of inattentiveness, distractibility, and persistence that consists of seventeen items; (2) Extroversion, a measure of non-shyness and comfort in new situations and social interactions that is comprised of eleven items; and (3) Interpersonal Affect which measures cooperation with a tendency to be argumentative and contains thirteen items. Derived aplha coefficients for the three components were $.92, .83$, and .86 respectively. The sample used included 183 subjects.

The SPAF was externally validated by comparing the relationships of its three components to eleven dimensions of the DESB, a measure of school adjustment. The eleven 
dimensions included: Classroom Disturbance, Impatience, Disrespect-Defiance, External Blame, Achievement Anxiety, External Reliance, Comprehension, Inattentive Withdrawn, Irrelevant Responsiveness, Creative Initiative, and Need for closeness to the Teacher. A stepwise multiple regression using the DESB factors as predictor variables and each of the SPAF components as a criterion variable yielded Multiple $R$ coeffiecients of .88 for Non-compliance, .70 for Extroversion, and .86 for Interpersonal Affect. Non-compliance and Interpersonal Affect were highly predictable from the DESB school behavior scales while Extroversion was moderately predictable of the same. A clear relationship between the SPAF and school adjustment was therefore established.

Further validation of the SPAF was accomplished by comparing the three components to standardized achievement test scores (CTBS; McGraw-Hill, 1982). In this multiple regression analysis, the 43 item SPAF predicted CTBS Reading and Math achievement scores with coefficients of .57 and .44 respectively. (For a detailed description of the SPAF, see Baker \& Velicer, 1986).

Procedure

According to Everitt (1980), the number of groups generated in a cluster analysis depends not only on the nature of the measured attributes but also increases with their number. Consequently, the use of principal components instead of raw items is recommended. Principal 
components are also useful because of their independent properties which make them distinct from one another.

Scaled scores of the three principal components (PCs) generated from the SPAF (Non-compliance, Interpersonal Affect, and Extroversion) were the variables used in the present cluster analysis. These scaled scores were derived for each component by forming summed scores that gave unit weighting to those items that loaded at the absolute value of . 40 and above. Items that had a negative component loading were reflected before forming scaled scores. The resulting scores were therefore relatively distinct although they were not orthogonal. In this study, the three scaled derivatives of the PCs were relatively distinct from one another. They were standardized and subsequently cluster analyzed.

\section{Cluster Analysis}

"Similarity measure" refers to the four measures or coefficients that are used in cluster analysis. In social science research, only two of the four have been used to analyze data: the correlation coefficient and the Euclidian distance measure. The latter is a difference measure - two subject scores are identical if each one is described by variables within the same magnitude so the distance between them is zero (Aldenderfer \& Blashfield, 1984 ).

Unlike the correlation coefficient which clusters subjects whose profiles are parallel, sharing scores with 
the same linear relationship irrespective of how far apart they are, a distance measure is affected by elevation or magnitude differences and recovers average profile levels (Everitt, 1980). In the present study, a subject's numeric value on each of the three component scores is critical two subjects who have parallel profiles that are numerically different must be grouped as being different. A noncompliant, introvert who does not relate well to others is in fact very different from a compliant extrovert who does relate well. Consequently, the selected measure must preserve that difference. In the present project, the Euclidian distance measure is most suitable.

of those algorithms that employ the distance metric, the hierarchical agglomerative methods were selected. These methods search a similarity matrix and merge the most similar cases sequentially until only one cluster remains. This merging is represented visually by a tree diagram or dendogram. Although at least a dozen of these methods have been developed, only four have been widely used and researched. These are: single linkage, complete linkage, average linkage, and Ward's method (Aldenderfer \& Blashfield, 1984).

In the present study, Ward's was selected as the primary method for four reasons. First, Monte Carlo studies have determined that it is a superior method for uncovering the presence of natural clusters in a data set (Milligan, 1981). Second, this is particularly true when most or all of the data points in the set are to be 
included (Aldenderfer \& Blashfield, 1984). In the present investigation, complete or near complete data coverage was expected. Third, in the present study, cluster overlap, another feature for which Ward's is best suited, was apparent among the three SPAF components. For example, while two separate groups of children might share the same scores and be introverted, they might have divergent values on the Non-compliance and Interpersonal scales. Fourth, it was expected that the present clusters would be spherical. This is still another characteristic for which ward's is designed.

The use of two clustering methods is recommended as a means of validating the type and number of clusters generated in any project (Aldenderfer \& Blashfield, 1984). If the clusters derived with each method are the same or very similar, the results are more robust and can be more reliably interpreted. In the present study, the average linkage method was utilized to cross-validate the results generated by Ward's. This method was selected because, like Ward's, research ha's demonstrated sound results (Milligan, 1981). Furthermore, this method does not require total inclusion of the data set and is less sensitive to the presence of outliers (extreme scores that fall significantly outside of the normal population and are too small in number to be interpretable). These two factors were potentially characteristic of the SPAF data and so validating the results with a method that accounted for them was important. 
Lastly, in addition to the use of two clustering methods in this project, the two samples that were analysed served as a double cross-validation. This is cautious, but warranted, given the youth and subjective nature of cluster analysis. 
The three SPAF principal components: Non-compliance, Extroversion, and Interpersonal Affect, were standardized and subsequently utilized as the variables in the cluster analysis. Two hierarchical methods that use the Euclidean distance metric were selected. Ward's algorithm was chosen as the primary method. Group average was selected as the secondary method and used in order to validate the results generated by Ward's. Both methods were applied to two independent data sets.

The value for $k$ or the number of clusters was determined subjectively by examining large changes of level or clumping in the tree diagrams produced with the SAS program "CLUS" (Luginbuhl, Scholtzhauer, \& Parker, 1987). This is considered indicative of the correct number of groups that are naturally present in the data (Everitt, 1980).

In the first data set, close examination of the tree diagram produced by Ward's method of cluster analysis revealed the presence of six or seven clumps of subjects that were separate and distinct levels within the dendogram. These six or seven excluded some subjects or small groups who were outliers with small group membership and considered uninterpretable.

The first data set was subsequently analyzed using the group average clustering method. By comparing the memberships in the clusters generated with ward's method to 
those generated with the group average method, it was determined that the six cluster solution generated with Ward's remained stable across methods (see Appendix A). In the second data set, close examination of the tree diagram produced with the SAS program "CLUS" and Ward's method revealed the presence of 6 or 7 clumps which appeared as separate and distinct levels within the dendogram. Again, these clumps excluded some subjects whose groups were small and considered uninterpretable. The second data set was also further cluster analyzed using the group average method. By comparing the clusters generated with Ward's method to those generated with group average, it was determined that the membership for a six cluster solution remained stable across methods (see Appendix B). Again, various numbers of clusters were initially generated so that the small, uninterpretable groups could be excluded.

Table 1 presents the standardized means in T-scores $(M=50 ; S D=10)$ of the three components: Non-compliance, Extroversion, and Interpersonal Affect, for the six cluster solutions found in the first data set. While a mean of 50 indicated an average range on any component score, a score of 40 , which was one standard deviation below the mean, represented a low value. Conversely, a score of 60 , one standard deviation above the mean, represented a high value. Thus, a score of 40 on the Non-compliance scale, for example, indicated a person was very compliant while a score of 60 indicated non-compliance. A low score of 40 on 
the Interpersonal Affect scale reflected a student had a well developed ability to get along with other children while a high score of 60 reflected an argumentative and disagreeable child. Last, a low score on the Extroversion scale reflected an introverted behavioral style; a high score indicated extroversion.

Table 1

Means and Standard Deviations of SPAF Components: Non-compliance, Extroversion, Interpersonal Affect for All Six Clusters, $N(1)$.

Variable

Non-comp

Extro

Intaff

Non-comp

Extro

Intaff

Non-comp

Extro

Intaff

Non-comp

Extro

Intaff

Non-comp

Extro

Intaff

Non-comp

Extro

Intaff
N

Mean

Cluster 1

22

22

22

11

11

11

12

12

12

13

13

13

9

9

6

6

6

41.87

51.47

43.16

Cluster 2

43.57

46.04

55.81

53.57

56.62

56.22

37.91

37.81

37.71

63.34

46.77

64.69

65.93

68.54

59.79
3.76

4.79

4.72

4.51

3.74

3.54

Cluster 3

3.48

4.90

3.36

Cluster 4

2.96

4.41

2.49

Cluster 5

4.87

4.65

4.21

Cluster 6

3.36

6.90 
Results indicated that the typical student in cluster

1 was very compliant, neither introverted nor extroverted, and had a well developed ability to get along with other children. The 22 students in this cluster could be viewed as easy. Their profiles captured an easy-going behavioral style -- very compliant, confident, and compatible (see figure 1). This cluster was therefore called the "EasyCompliant" group.

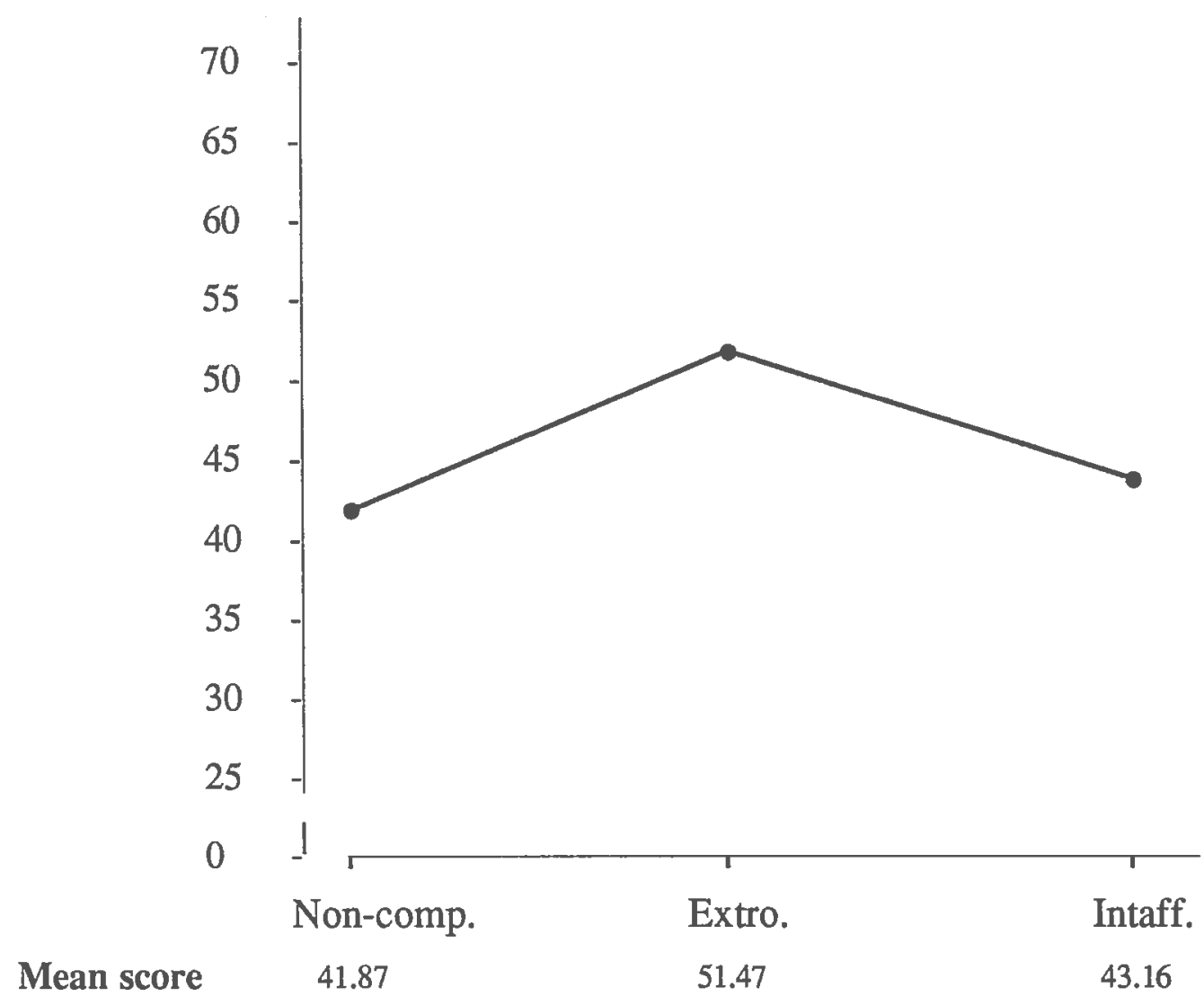

Figure 1. Mean scores on Non-Compliance, Extroversion, and Interpersonal Affect for Easy-Compliant cluster ( $\mathrm{N}=22)$. 
The typical student in cluster 2 was also characterized by a profile with high compliance and moderate introversion/extroversion scores. However, the 11 students in cluster 2 were differentiated by a highaverage Interpersonal Affect score indicating that although these children got along with others, they also demonstrated some competitive and argumentative behaviors with peers (see figure 2). This cluster was therefore named the "Easy-Assertive" group.

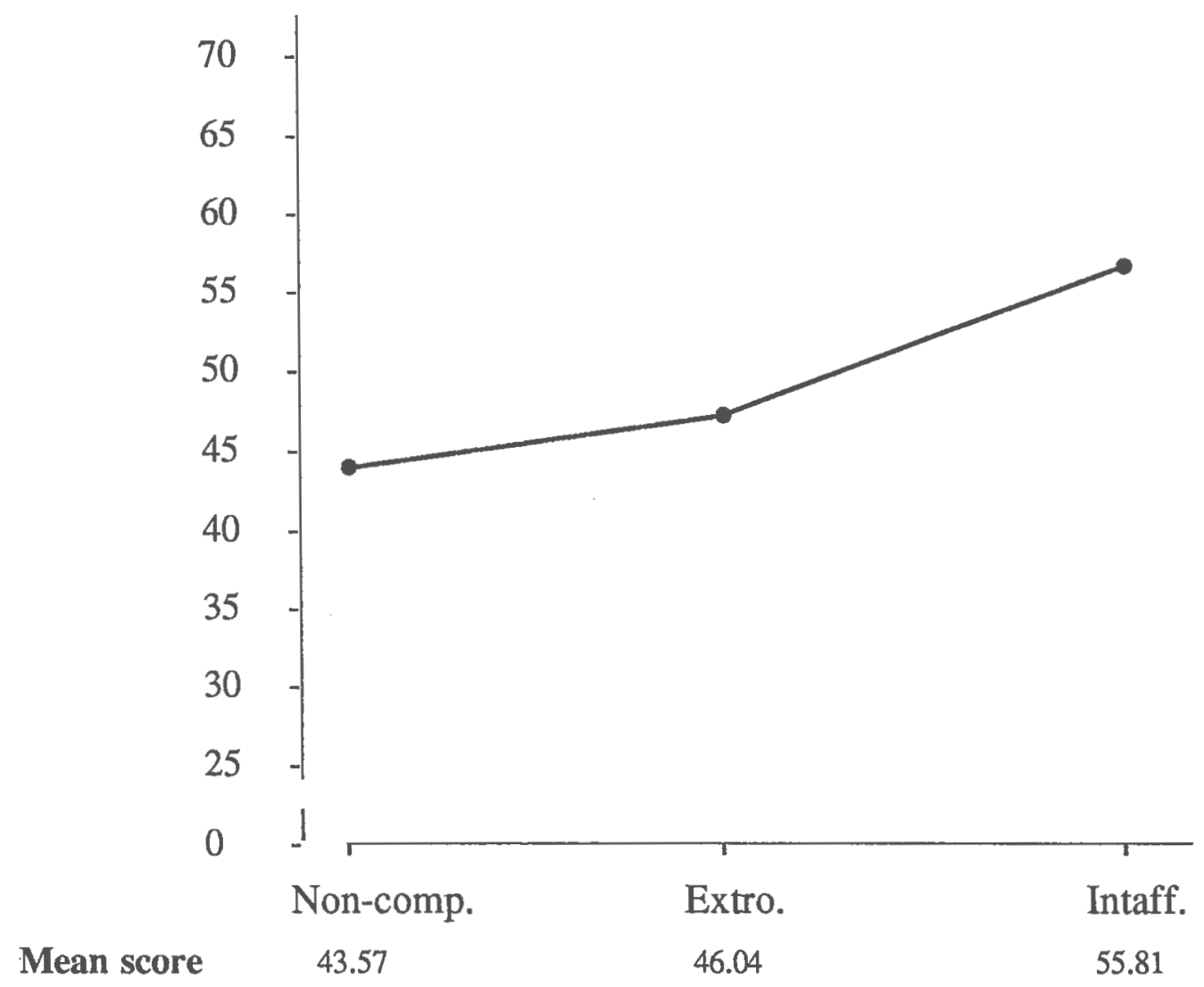

Figure 2. Mean scores on Non-Compliance, Extroversion, and Interpersonal Affect for Easy-Assertive cluster ( $N=11)$. 
The 12 students in cluster 3 were characterized by being moderately compliant and in the high-average extroversion range suggesting that these children were active, although sometimes distractible participant in most classroom activities. The average child in cluster 3 was also described with a high-average Interpersonal Affect score again indicating that although generally compatible with his/her classmates, this child also demonstrated some competitive and argumentative behaviors (see figure 3 ). This cluster was labeled "Moderately DifficultExtroverted."

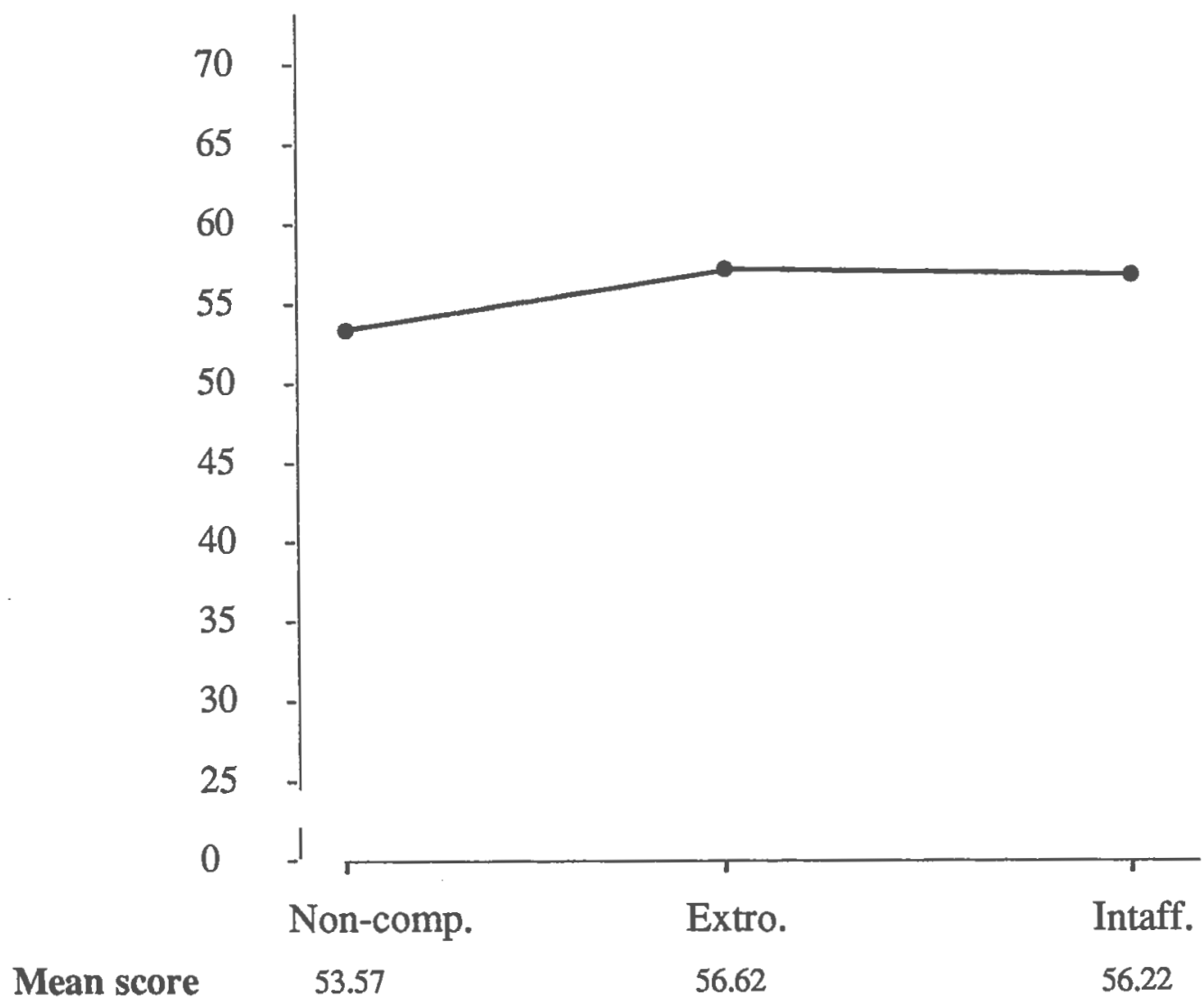

Eigure 3. Mean scores on Non-Compliance, Extroversion, and Interpersonal Affect for Moderately Difficult-Extroverted cluster $(\mathrm{N}=12)$. 
The typical child in cluster 4 attained extreme scores for Compliance and Interpersonal Affect and Introversion (see figure 4). This very compliant and friendly child was also extremely shy and very reluctant to participate in group activities. Consequently this cluster was called the "Easy-Withdrawn" group.

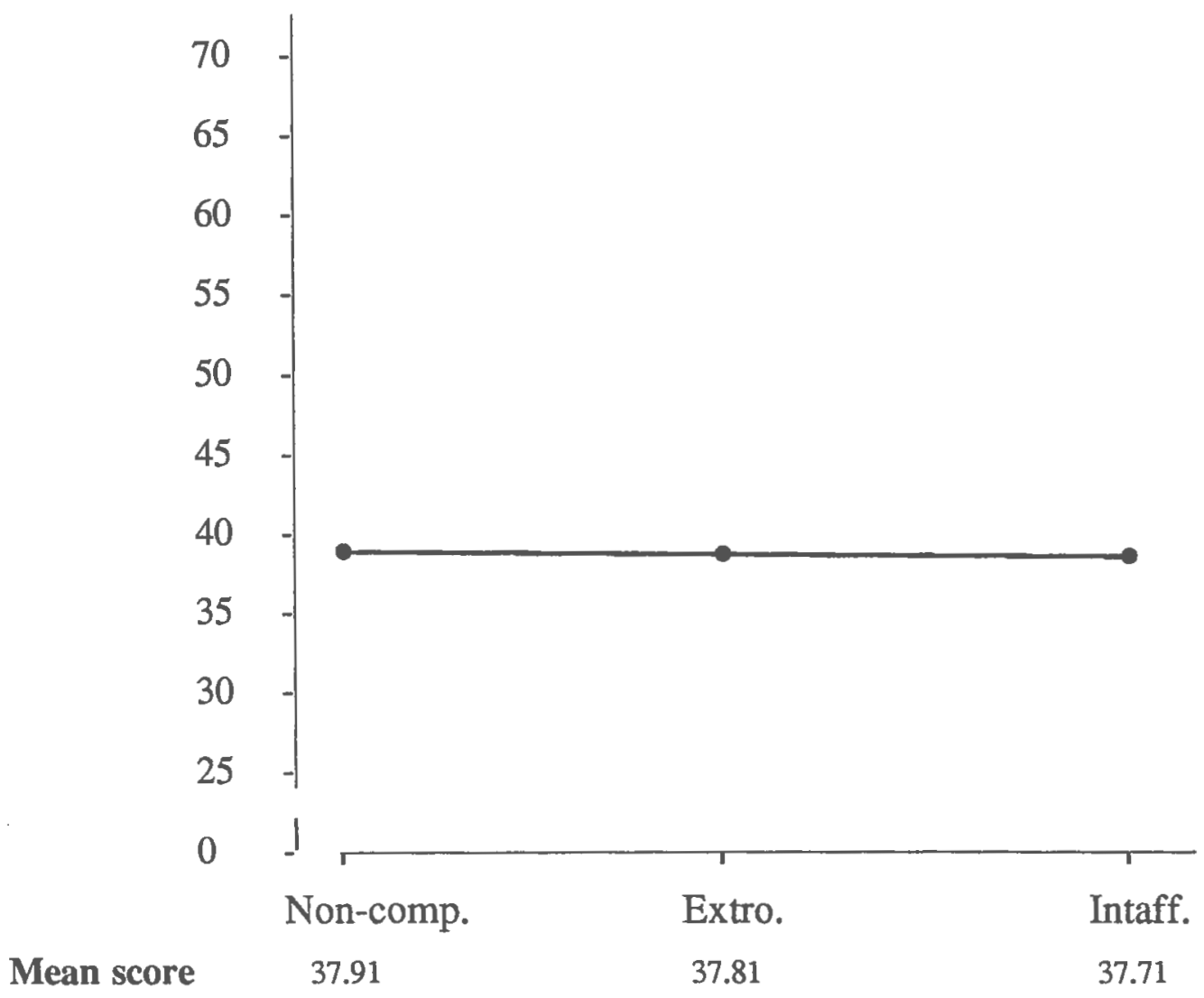

Figure 4. Mean scores on Non-Compliance, Extroversion, and Interpersonal Affect for Easy-Withdrawn cluster ( $\mathrm{N}=13)$. 
The average student in cluster 5 departed significantly from the first four groups with large values on the Non-compliance and Interpersonal Affect scales indicating non-compliance and an inability to get along with others as marked by argumentative, competitive and aggressive behaviors. This difficult type of student earned at the same time a high-average score on the Extroversion scale indicating a tendency to be inattentive and to withdraw (see figure 5). This group was labeled "Difficult-Withdrawn."

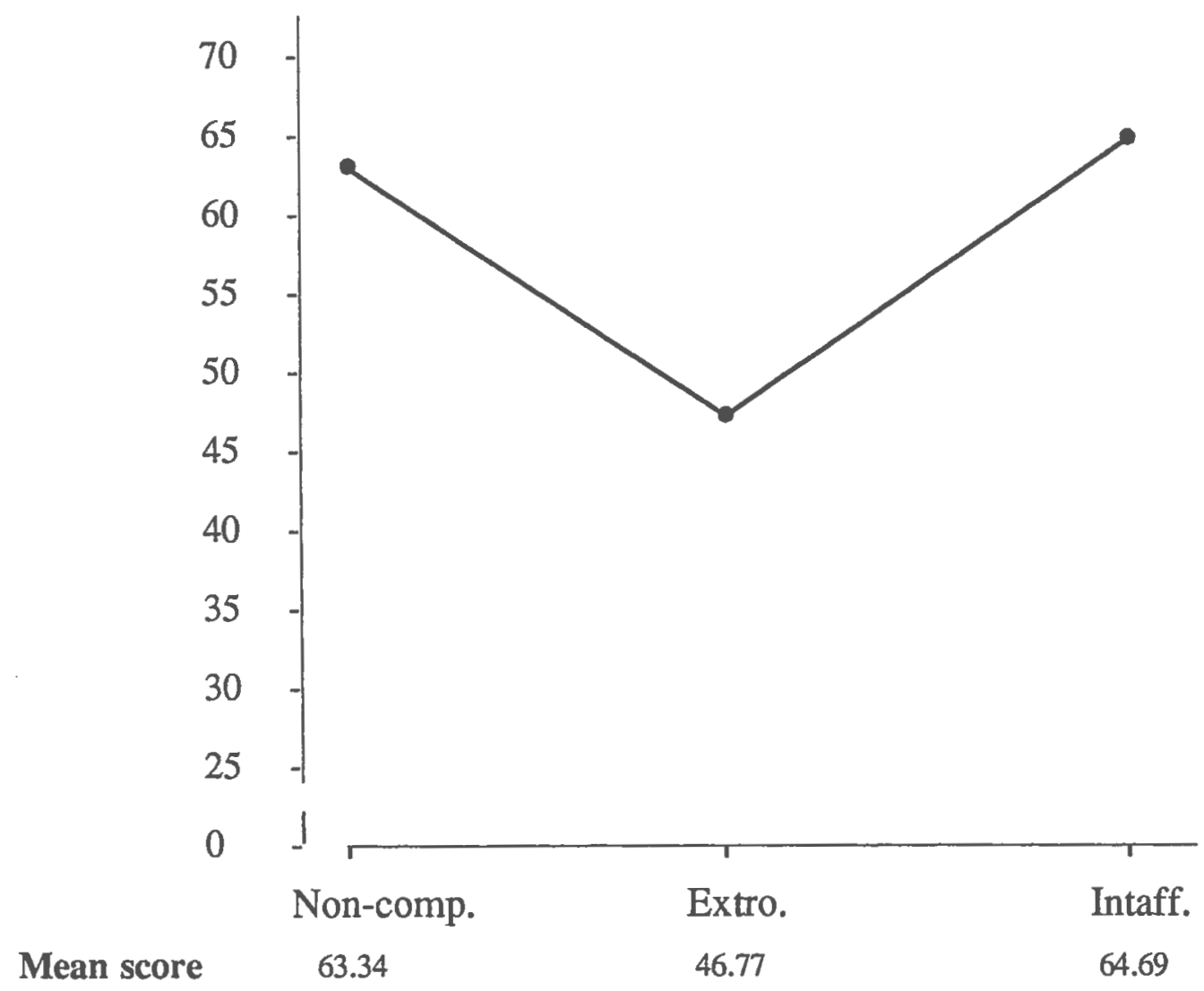

Figure 5. Mean scores on Non-Compliance, Extroversion, and Interpersonal Affect for Difficult-Withdrawn cluster ( $\mathrm{N}=9$ ). 
Also difficult in nature was the average student in cluster 6 who was again described by extreme noncompliance and limited ability to get along with others. Unlike the typical student in cluster 5, however, the typical student in cluster 6 was differentiated by an extremely high extroversion scale indicating that this child acted out a great deal (see figure 6). This group was consequently named the "Difficult-Extroverted" group.

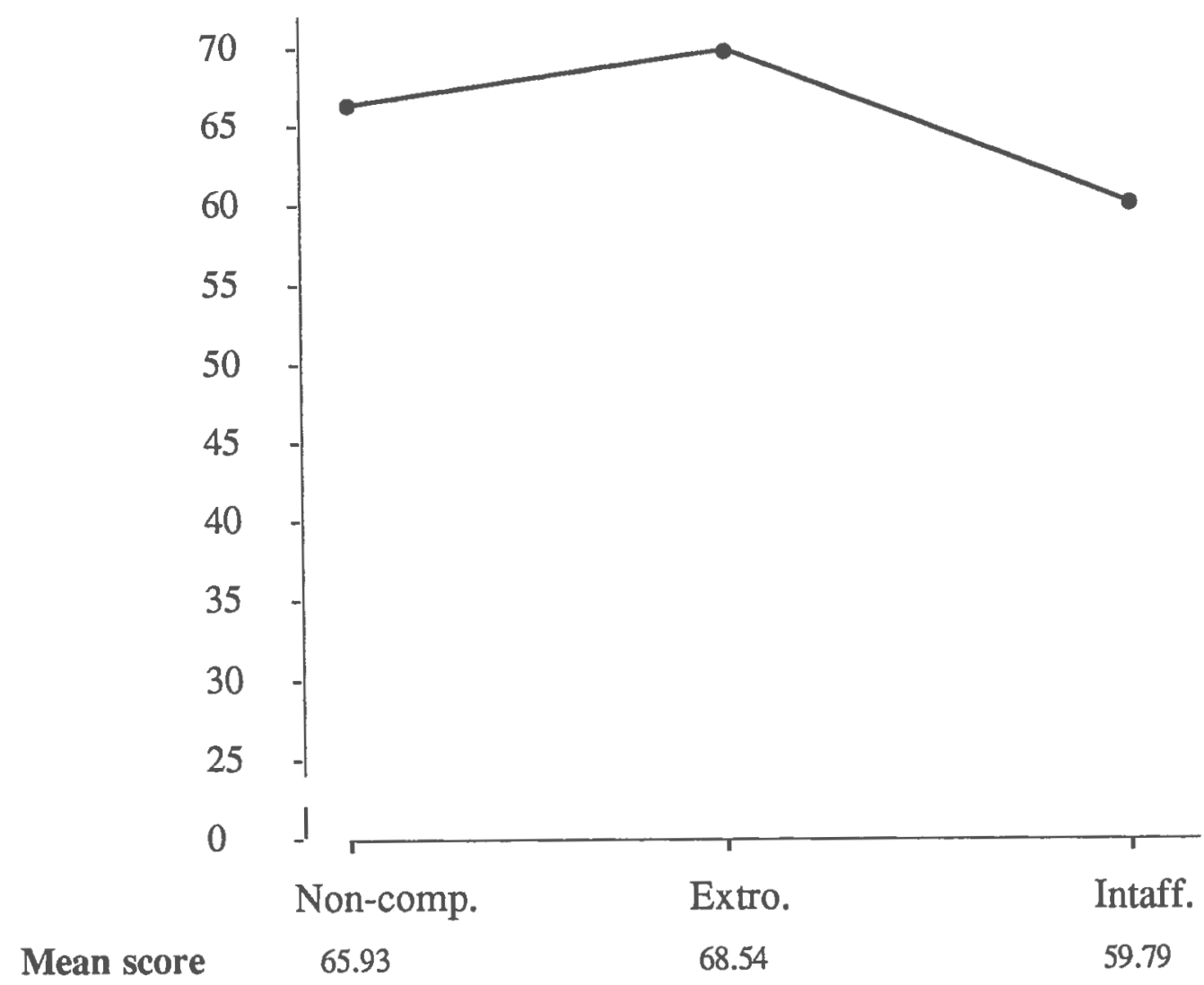

Figure 6. Mean scores on Non-Compliance, Extroversion, and Interpersonal Affect for Difficult-Extroverted cluster $(N=6)$. 
Table 2 presents the standardized means ( $M=50 ; S D=10)$ of the three SPAF components for each of the six cluster solutions found in the second data set. As in the first data set, the three PCAs were standardized with T-scores. While 50 was the mean, a score of 40 represented a low value on any of the three components and a score of 60 reflected a high value.

Table 2

Means and Standard Deviations of SPAF Components: Non-compliance, Extroversion, and Interpersonal Affect for All Six Clusters, $N(2)$.

Variable N Mean S.D.

Non-comp

Extro

Intaff

Non-comp

Extro

Intaff

Non-comp

Extro

Intaff

Non-comp

Extro

Intaff

Non-comp

Extro

Intaff

Non-comp

Extro

Intaff
10

10

10

31

31

31

16

16

16

14

14

14

23

23

23

6

6
Cluster 1

55.91

58.90

46.51

3.46

2.92

2.60

Cluster 2

45.70

3.86

53.55

2.85

43.92

3.33

Cluster 3

63.43

6.24

50.67

70.44

7.02

5.68

Cluster 4

38.15

34.77

$4 \cdot 18$

43.03

3.31

3.98

cluster 5

42.48

46.71

43.97

3.04

2.82

3.98

Cluster 6

66.34

2.81

62.52

4.12

57.99 
Similar to the first data set, each of the clusters generated from the second data set was distinct. Furthermore, five of the six clusters were comparable across samples. For example, cluster 2 was like the "EasyCompliant" group in the first data set: compliant, neither extroverted nor introverted, and socially cooperative with other children. Cluster 4 was similar to the "EasyWithdrawn" group in the first data set with the average child being extremely compliant and cooperative with others as well as extremely withdrawn.

The average student in cluster 1 shared characteristics with the "Moderately Difficult-Extroverted" student in the first data set. This student was also described as being moderately non-compliant and moderately extroverted. However, unlike the student from the first data set, the Moderately Difficult-Extrovert in the second data set demonstrated good ability to get along with his/her peers.

The typical student in cluster 3 was more introverted than extroverted and consequently shared a profile similar to the "Difficult-Withdrawn" cluster in the first data set. This "Difficult-Withdrawn" group in the second data set had a high non-compliance score and an extremely high score on Interpersonal Affect indicating an attitude of disrespect and incompatability with others.

Last, like those students who fell into the "DifficultExtroverted" cluster in the first data set, the 6 students in cluster 6 were also extremely non-compliant, non 
-compatible, and very extroverted as reported by their teachers.

The final cluster was not comparable across data sets. The average student in cluster 5 was described as being very compliant, more introverted than extroverted, and highly compatible with peers. This "Easy-Shy" group did not clearly match the "Easy-Assertive" group from the first data set. Neither clusters, therefore, were replicated across sample sets. However, both fell within the "easy" range. 


\section{Discussion}

This study utilized cluster analysis in order to empirically test the hypothesis that temperament groups are present among normal populations of children. Because cluster analysis is a new and potentially subjective statistical procedure, two clustering algorithms as well as two sample groups were used. This served to double cross validate the findings. The clusters derived from both Ward's method and the average linkage method were very similar and therefore demonstrated that the results were robust and could be more reliably interpreted.

While the three groups delineated in the NYLS: the Easy, Slow-To-Warm-Up, and Difficult constellations, were not distinctively recovered, the six groups that did emerge in each data set could be viewed as variations of the three. Each of the six groups was distinctively different. Five of the six groups were similarly recovered in each data set with three of those five (the two Difficult groups and the one Easy-Withdrawn) being almost the same across samples. 


\section{STUDY 2: A MULTIVARIATE ANALYSIS OF VARIANCE COMPARING THE SIX CLUSTERS}

Method

Sample

These data were obtained through school records between 1982 and 1984. They included the math and reading Comprehensive Test of Basic Skills scores (CTBS: McGrawHill, 1982) which was administered to all children in the target school district. All of the information pertained to the same kindertgarten, first, and second grade children as in the first study. The total sample size equaled 231. However, complete information was available for only 39 of the 73 students who were clustered in the first data set and for 79 of the 100 subjects clustered in the second data set. Twenty-one teachers from five schools volunteered to participate.

\section{Instruments}

The Comprehensive Test of Basic skills (CTBS) is a timed test that is administered in a group. It is normreferenced and designed to measure student achievement in reading, math, spelling, language, science, and social studies. Scores are reported in national and local percentiles, stanines, and grade equivalents.

The validity of the test is based on the percentage of students within the normative sample (approximately 250,000 students with between 3,028 and 18,992 for a given grade 
and test level) who exhibited mastery at a given grade and level. Bayesian estimates of percentage correct equal a .75 mastery criterion. (Buros, 1987). Conventional reliability estimates are not reported in the Preliminary Technical Report.

This study used the stanines because they are standardized and comparable across grade levels. Only reading and math grades were included. For this sample the mean stanines were 4.1 in both reading and math with standard deviations of 2.7 and 2.6 respectively. 
In the present study, five of the clusters in the first data set and all six of the clusters in the second data set were treated as the independent variables and compared to one another in two multivariate analyses of variance. Cluster 5 in the first data set was omitted because achievement test scores were available for only one subject. The multivariate analysis of variance was useful for external validation. In order to externally validate the presence of clusters recovered in a data set, it is recommended that they be compared to one another with new dependent variables that are different from the clustering variables. In the present study, two dependent measures of school performance were used: the CTBS math and reading scores.

The multivariate analysis of variance found overall statistical significance when the five groups in data set 1 were compared to one another on the two measures of achievement, Wilks lambda, $F(4,34)=2.24, \mathrm{p}<.05$. Individual follow-up one-way analyses of variance, however, indicated statistical significance for the math stanine alone, $F(4,31)=3.11, p<.05$. Subsequent Tukey Tests comparing each group to one another revealed that the significant difference in math stanine scores was limited to that difference between clusters two and five: the "Easy-Assertive" and "Difficult-Withdrawn" groups. Mean and standard deviation math scores for each cluster are 
depicted in Table 3 (see Table 3 ).

Table 3

Cluster Means and Standard Deviations for CTBS Math and Reading Stanines, N (1).

Math Stanine

Reading Stanine

\begin{tabular}{lcccc} 
Group & Mean & S.D. & Mean & S.D. \\
\hline $\begin{array}{c}\text { Cluster } 1 \\
(n=14)\end{array}$ & 5.36 & 1.74 & 6.07 & 1.90 \\
$\begin{array}{c}\text { Cluster } 2 \\
(n=7)\end{array}$ & 7.00 & 1.16 & 6.57 & 1.51 \\
$\begin{array}{c}\text { Cluster } 3 \\
(n=6)\end{array}$ & 6.00 & .89 & 6.00 & 1.27 \\
$\begin{array}{c}\text { Cluster } 4 \\
(n=9)\end{array}$ & 6.00 & 1.12 & 5.56 & 1.33 \\
$\begin{array}{c}\text { cluster } 6 \\
(n=3)\end{array}$ & 4.00 & 1.00 & 3.67 & 1.16 \\
Entire & 5.80 & 1.51 & 5.85 & 1.66
\end{tabular}

Sample

$(n=39)$

In the second data set, a multivariate analysis of variance also found overall statistical significance when the six clusters were compared to one another with the same two dependent measures of achievement, Wilks lambda, $F(5,73)=5,84, p<001$. This time individual, follow-up oneway analyses of variance indicated statistical significance for both of the dependent variables: reading stanine, $F(5,73)=11.22, p<.001$, and math stanine, $F(5,73)=8.56$, p $<.001$.

Follow-up Tukey Tests for both dependent variables revealed multiple differences between groups (see Appendix D). With the reading stanine, significant differences existed between cluster 6 and clusters 5, 2, and 4; cluster 
1 and clusters 2 and 4; and cluster 3 and 4. These differences demonstrated that the "Difficult-Extroverted" group scored, on the average, significantly lower on the CTBS reading test than did the "Easy-Shy," the "EasyCompliant," and "Easy-Withdrawn" groups. Similarly, the "Moderately Difficult-Extroverted" cluster achieved a mean stanine significantly lower than the "Easy-compliant" and "Easy-Withdrawn" groups. And last, the "DifficultWithdrawn" cluster scored significantly below the "EasyWithdrawn" cluster. The means and standard deviations for the CTBS math and reading stanines for all six clusters are depicted in Table 4.

Table 4

Cluster Means and Standard Deviations for CTBS Math and Reading stanines, N (2). Math stanine Reading stanine

\begin{tabular}{|c|c|c|c|c|c|}
\hline Group & & Mean & S.D. & Mean & S.D \\
\hline $\begin{array}{c}\text { Cluster } \\
(n=9)\end{array}$ & 1 & 4.22 & .97 & 3.78 & 2.39 \\
\hline $\begin{array}{l}\text { Cluster } \\
(n=26)\end{array}$ & 2 & 6.00 & 1.36 & 6.27 & 1.25 \\
\hline $\begin{array}{c}\text { Cluster } \\
(n=14)\end{array}$ & 3 & 4.07 & 1.69 & 4.14 & 1.51 \\
\hline $\begin{array}{c}\text { Cluster } \\
(n=9)\end{array}$ & 4 & 6.78 & 1.30 & 7.44 & 1.67 \\
\hline $\begin{array}{r}\text { cluster } \\
(n=16)\end{array}$ & 5 & 5.44 & .89 & 5.63 & 1.78 \\
\hline $\begin{array}{c}\text { Cluster } \\
(n=5)\end{array}$ & 6 & 3.80 & 1.79 & 2.40 & 1.52 \\
\hline $\begin{array}{l}\text { Entire } \\
(n=79)\end{array}$ & Sample & 5.29 & 1.62 & 5.37 & 2.10 \\
\hline
\end{tabular}


On the math stanine, Tukey Tests revealed significant differences between cluster 6, the "Difficult-Extroverted" cluster, and clusters 2 and 4: the "Easy-Compliant" and "Easy-Withdrawn" groups. Differences between cluster 3, the "Difficult-withdrawn" group and clusters 2 and 4 were also significant. And last, the "Moderately DifficultExtroverted" group, cluster 1, also scored a mean stanine that was significantly lower than clusters 2 and 4 , the "Easy-Compliant" and "Easy-Withdrawn" groups (see Appendix E). 
Discussion

Results from these two studies provide evidence to suggest that within the normal population, many children do, in fact, tend to exhibit one of a few personality or temperament types as measured by the student Personality Assessment Form (SPAF). Accordingly, many children may be grouped with others who share similar behavior styles. Although the three distinct temperament constellations (Easy, Slow-To-Warm-Up, and Difficult) described in the NYLS were not clearly delineated in the present study, six variations of the three groups did emerge demonstrating consistency with the NYLS theory.

The first study utilized cluster analysis in order to empirically test the hypothesis that temperament groups are present among normal populations of children. Because cluster analysis is a new and potentially subjective statistical procedure, two clustering algorithms as well as two sample groups were used. This served to double crossvalidate the findings. The clusters derived from both Ward's method and the group average method were very similar and therefore demonstrated that the results were robust and could be reliably interpreted.

While the groups in both data sets fell within the Easy, Slow-To-Warm-Up, and Difficult ranges, like groups also emerged from both sample sets. Similar to previous findings (Thomas \& Chess; 1977; Bates et al., 1979) difficult groups were most clearly defined as indicated by 
their more extreme SPAF scores. For example, in both the first and second data sets, two groups of difficult students were recovered who shared similar SPAF profiles. The first group consisted of six subjects in each sample set and was characterized as being very non-compliant, having minimal interpersonal skills with peers, and displaying extroverted, aggressive, and acting-out behavior. The second group, which consisted of nine subjects from the first data set and 7 from the second data set, shared similar component scores for non-compliance and interpersonal skills, but was distinguished by lower extroversion scores. Statistically, however, the typical student in this group was not rated as introverted or withdrawn as is suggested in the NYLS profile. Rather, these children were described as being neither introverted not extroverted.

The third and last group that also emerged as identifiably the same in both data sets fell within the easy range but was characterized by extreme compliance, extreme agreeableness or ability to get along with peers, and introversion. Whether or not this group taps into a Slow-To-Warm-Up group that has already adjusted or what has been elsewhere described as an inhibited type is unclear (Garcia Coll, Kagan, \& Reznick, 1984).

otherwise, the groups that emerged within the easy range were not distinctively the same across sample sets. Each had somewhat different SPAF profiles although all hovered around the mean. 
The primary finding of the second study was that some of the six groups that were derived from SPAF scores in each data set were also significantly different from one another in terms of school achievement. Furthermore, those clusters that differed from one another in terms of achievement were divided according to the characteristic "Difficult" and non-compliant versus "Easy" and compliant cluster types. The multivariate analysis of variance utilizing standardized achievement (CTBS) scores therefore served to externally validate the integrity of all the clusters but the Easy-Assertive cluster in the first data set and the Easy-Shy cluster in the second data set. This provided evidence to support the expected relationship between temperament and school achievement. In general, the more difficult groups did score significantly below the characteristically easier types.

It should be emphasized that MANOVA results from the two data sets varied. The analysis from the first data set which recovered significant differences between the "EasyAssertive" and "Difficult-Withdrawn" groups for math achievement scores alone was particularly limited because of the small and unequal sample sizes among groups. The increased sample size and resulting larger group sizes in the second data set rendered the second analysis more informative and reliable. However, without replication of the findings in an independent data set, the results cannot be regarded as conclusive. While results do strongly suggest that these groups can be differentiated from one 
another in terms of personality ratings as well as school achievement, subsequent research in which group sample sizes are larger is needed.

The major contribution of this study to psychological research is that the results provide a first, empiricallybased, documentation for the presence of temperament-based constellations of children that are present in a normal population. In order to verify the finding, however, replicative research that utilizes a similar methodology is essential. Furthermore, longitudinal research that examines the stability of group membership over time is also needed.

The present results also lend support to earlier findings that temperament is related to school achievement $\checkmark$ (Baker \& Velicer, 1986; Martin et al., 1988; Martin, 1987). Even more important, these findings also suggest that a child's temperament or personality style may be one important predictor of school achievement and success. For, in accordance with the original spirit of the NYLS research, the significance of temperament findings is not in grouping or "typing" children. Rather, it is in recognizing characteristics that may be precursors to dysfunctional development, or in this case, school failure. Specifically, those children whose profiles most nearly resemble a "difficult" group might benefit from intervention sevices to foster school success.

Clearly, research in temperament that continues to address the measurement issues or utilizes temperament 
scales whose psychometric properties are sound must be expanded before this still theoretical construct can be applied in psychological or educational practice. In addition to issues of scale reliability, issues of scale validity must also be explored. The continued research of children's temperament "types" and their relationship to school achievement, child rearing practices, environmental demands, and behavior disorders remain areas that are rich for investigation. 


\section{BIBLIOGRAPHY}

Aldenderfer, M. S. \& Blashfield, R. K. (1984). Cluster Analysis. Beverly Hills! Sage.

Baker, E.H., \& Velicer, W.F. (1986). The development and validation of the Student Personality Assessment Form (SPAF). Unpublished manuscript.

Baker, E. H., \& Velicer, W. F. (1986). The student Personality Assessment Form (SPAF): External

Validation. Unpublished manuscript.

\& Baker, E. H., \& Velicer, W. F. (1982). The structure and reliability of Teacher Temperament Questionnaire. Journal of Abnormal Child Psychology, 531-546.

Barron, A. P., \& Earls, F. (1984). The relation of temperament and social factors to behavior problems in three-year-old children. Journal of Child Psychiatry, $\underline{25}, 23-33$.

Bates, J. E., Freeland, C. A., \& Lounsberry, M. L. (197,9). Measurement of infant difficultness. Child Development, 50, 794-803.

Buros, Oscar K. (Ed.). (1987). Mental Measurements Yearbook. Highland Park, N. J.: Gryphon.

- Buss, A. H., Plomin, R., \& Willerman, L. (1973). The inheritance of temperaments. Journal of Personality, $\underline{41}, 513-524$.

Everitt, B. (1980). Cluster Analysis. New York: Halsted.

Garcia Coll, C., Kagan, J., \& Reznick, S. (1984). Behavioral Inhibition in Young Children. Child Development , 51, 1157-1167.

- Goldsmith, H. H., \& Gottesman, I. I. (1981). Origins of variation in behavior style: a longitudinal study of temperament in young twins. Child Development, 53, 91 $-103$.

Hubert, N. C., Wachs, T. D., Peters-Martin, P., \& Gandour, M. J. (1982). The study of early temperament: measurement and conceptual issues. Child Development, $\underline{53}, 571-600$.

- Lerner, J. V. (1983). The role of temperament in psychosocial adaptation in early adolescents: a test of a "goodness of fit" model. The Journal of Genetic Psychology, 143, 149-157. 
Lerner, R. M. , Palermo, M. , Spiro, A. , \& Nesselroade, J. (1982). Assessing the dimensions of temperamental

individuality across the life span: The Dimensions of

Temperament Survey (DOTS). Child Development, 53, 149 -159 .

Lorr, M. (1983) - Cluster Analysis for Social Scientists. San Francisco: Jossey-Bass.

Luginbuhl, R. C., Schlotzhauer, S. D., \& Parker, J. C. (Eds.). (1987). SAS/STAT Guide for Personal Computers (6th ed.). Cary, NC: SAS.

Martin, R. P., Drew, K. D., Gaddis, L. R., \& Moseley, M. (1988). Prediction of Elementary School Achievement From Preschool Temperament: Three Studies. School Psychology Review, 17, 125-137.

Martin, R. P. (1987). The Georgia Temperament Project: overview of a Program of Research. Paper presented at the Biennual Meeting of the society for Research in Child Development, Baltimore, MD.

Martin, R. P., \& Pfeffer, J. (1983). Comparison of mothers' and fathers' temperament ratings of referred and nonreferred preschool children. Journal of Clinical Psychology, 39, 1013-1020.

- Martin, R. P. (1983). Temperament: a review of research with implications for the school psychologist. School Psychology Review, 12, 266-273.

McGraw-Hill. (1982). The Comprehensive Test of Basic Skills (Form V). Monterey, CA: Author.

Milligan, G. (1981). A review of Monte Carlo tests of cluster analysis. Multivariate Behavioral Research, 16, 379-407.

Rothbart, M. K. \& \& Derryberry, D. (1981). Development of Individual Differences in Temperament in $M$. $E$. Lamb and A. C. Brown (Eds) Advance in Developmental Psychology (vol. 1) Hillsdale, N. J.: Lawrence Erlbaum.

Sattler, J. M. (1982). Assessment of Children's Intelligence and Special Abilities. Boston: Allyn and Bacon.

R. Seifer (personal communication, October 22, 1986)

Spivack, G., \& Swift, M. S. (1967). The Devereux Elementary School Behavior Rating scale. Devon, PA: Devereux Foundation. 
Thomas, A., \& Chess, S. (1977). Temperament and Development. New York: Brunner/Mazel.

Thomas, A., Chess, S., Birch, M., Hertzig, M., \& Korn, S. (1963). Behavioral Individuality in Early Childhood. New York: New York University Press. 
APPENDIX A

Cluster Stability Across Ward's and Group Average Methods $\mathrm{N}$ (1) 
Table 5

\section{Cluster Stability Across Ward's and Group Average Methods N (1)}

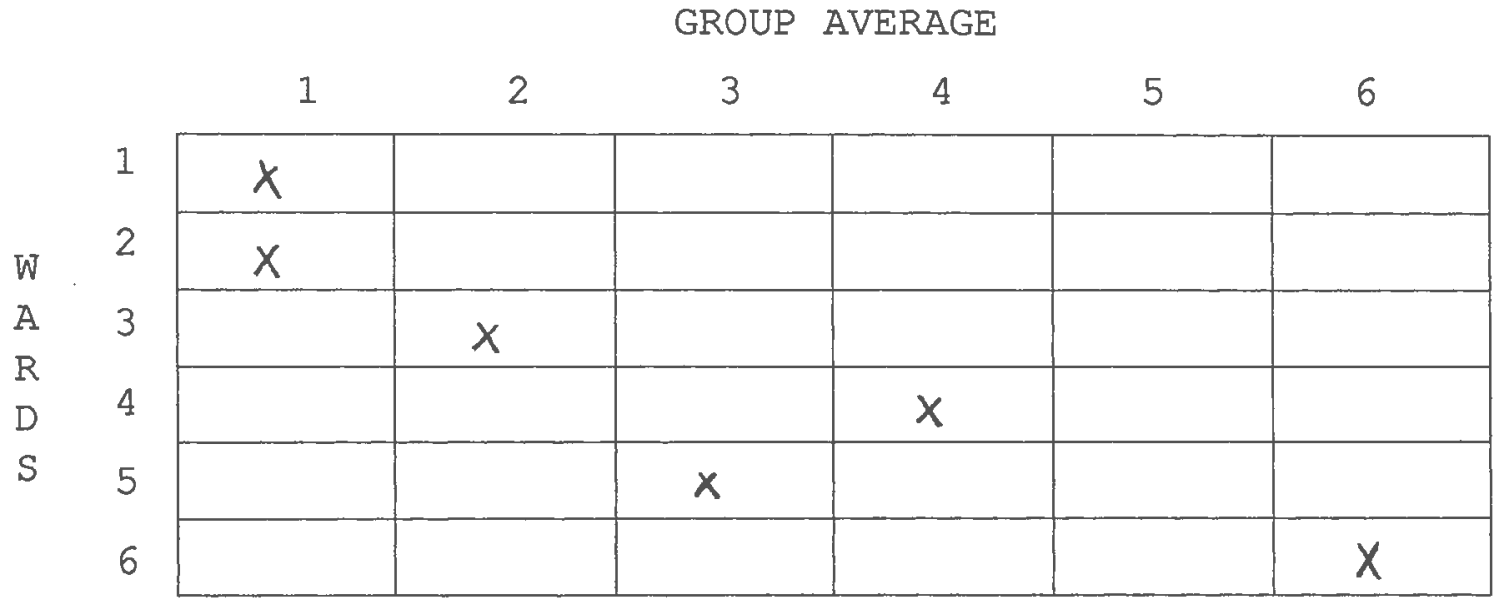

WARD'S METHOD

cluster 1

cluster 2

cluster 3

Cluster 4

cluster 5

Cluster 6
GROUP AVERAGE METHOD

cluster 1

Cluster 1

Cluster 2

Cluster 4

cluster 3

cluster 6

Note. When an equal sign is not indicated, the integrity of the Ward's cluster was maintained in the indicated average cluster. 


\section{APPENDIX B}

\section{Cluster Stability Across Ward's and Groub Average}

Methods N (2) 
Table 6

Cluster Stability Across Ward's and Group Average Methods $\underline{N(2)}$

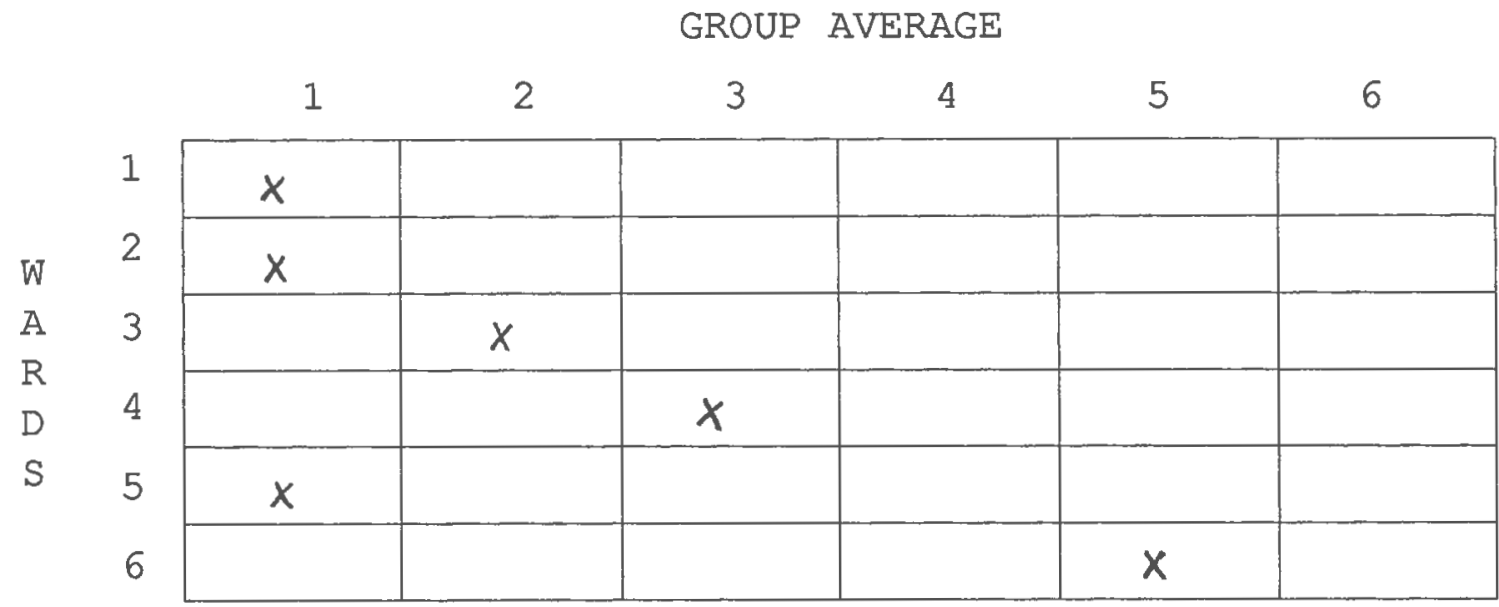

WARD'S METHOD

cluster 1

Cluster 2

cluster 3

$183,186)$

Cluster 4

cluster 5

Cluster 6
GROUP AVERAGE METHOD

cluster 1

cluster 1

cluster $2+$ cluster 8 (subjects

Note: When an equal sign is not indicated, the integrity of the Ward's cluster was maintained in the indicated average cluster. 


\section{APPENDIX C}

Student Personality Assessment Form (SPAF)

(Forty Three Item) 
student Personality Assessment Form (SPAF)

1. Child tends to return to interrupted activities.

2. Child will accept a substitute if the work or play activity desired is unavailable.

3. Chils is shy with unfamiliar adults.

4. Child can be talked out of a bad mood easily.

5. Child is easily distracted from work by noises or movement.

6. Child argues with other children.

7. Child prefers to watch new activities rather than participate.

8. Child comments about the class being either hot or cold.

9. Child becomes impatient and goes to another task if the original task is difficult to understand or do.

10. Child becomes upset when other child wins a game.

11. Child overcomes reluctance to participate in new activities very quickly.

12. Child is sensitive to bright light.

13. Child will persist at one activity for a long period of time if allowed.

14. Child becomes overly upset in stressful situations.

15. Child adapts slowly to changes in physical location such as seating arrangement, etc.

16. Child is aware of changes in the level of light in the room (brighter or dimmer).

17. Child starts but does not finish class work.

18. Child complains about other children.

19. Child readily becomes involved with new activities and situations.

20. Child notices new or unusual clothes worn by others.

21. Child fidgets or wiggles even when involved in an activity.

22. Child communicates disagreement to other children by fighting and yelling.

23. Child adjusts slowly to new situations.

24. Child enjoys doing tasks for the teacher.

25. Child can attend to what the teacher is saying even when other children are being noisy.

26. Child becomes upset or angry when not allowed to engage in a desired activity.

27. Child is shy with children who are unfamiliar.

28. Child reports accidents or rule infractions to the teacher.

29. Child is easily sidetracked.

30. Child takes a loss in competitive situations lightly.

31. Child enjoys telling stories or doing other activities in front of the class.

32. Child can follow verbal instructions.

33. Child stays with a task for only a short time before switching to another.

34. Child says things to make other children feel bad.

35. Child prefers familiar toys and games to new play.

36. Child can explain his needs or desires to others. 
37. Child finishes work before it is due.

38. Child bullies other children.

39. Child plunges into new activities and situations without hesitation.

40. Child gives irrelevant answers to questions.

41. Child kicks or hits other children.

42. Child misses recess because of incomplete work.

43. Child teases other children cruelly. 


\section{APPENDIX D}

Tukey Test Results: Significant Mean Reading Score Differences Between Clusters in second Data set 
Table 7

Tukey Test Results: Significant Mean Reading Score Differences Between Clusters in Second Data set

\begin{tabular}{|c|c|c|c|c|c|}
\hline Clusters & 1 & 3 & 5 & 2 & 4 \\
\hline Difficult-Extroverted & 1.38 & 1.74 & $3.23 *$ & $3.87 *$ & $5.04 *$ \\
\hline Mod.Difficult-Extroverted & & .36 & 1.85 & $2.49 *$ & $3.66 *$ \\
\hline Difficult-withdrawn & & & 1.49 & 2.13 & $3.30 *$ \\
\hline Easy-Shy & & & & .64 & 1.81 \\
\hline
\end{tabular}


APPENDIX E

Tukey Test Results: Significant Mean Math Score Differences Between Clusters in Second Data set 
Table 8

Tukey Test Results: Significant Mean Math Score Differences Between Clusters in Second Data set

\begin{tabular}{|c|c|c|c|c|c|}
\hline Clusters & 3 & 1 & 5 & 2 & 4 \\
\hline Difficult-Extroverted & .27 & .42 & 1.64 & $2.20 *$ & $2.98 *$ \\
\hline Mod. Difficult-Extroverted & & .15 & 1.37 & $1.93 *$ & $2.71 *$ \\
\hline Difficult-Withdrawn & & & 1.22 & $1.78 *$ & $2.56 *$ \\
\hline Easy-shy & & & & .56 & 1.34 \\
\hline Easy-Compliant & & & & & .78 \\
\hline
\end{tabular}

